\title{
Genetic diversity and population genetics of the warble flies Hypoderma bovis and $H$. sinense in Qinghai Province, China
}

\author{
Yong $\mathrm{Fu}^{1,2}$, Wei $\mathrm{Li}^{2^{*}}$, Hong Duo ${ }^{2}$, Zhi-Hong Guo², Ying Li ${ }^{3}$ and Yan-Ming Zhang ${ }^{1 *}$
}

\begin{abstract}
Background: Hypoderma bovis and H. sinense (Diptera: Oestridae) mainly parasitise cattle and yaks. The two parasites are pathogenic and cause economic losses that result from reduced amounts of livestock products, including milk, meat, and skin. Genetic diversity and population genetic structure of $\mathrm{H}$. bovis and $\mathrm{H}$. sinense have not been evaluated, but could be used to inform appropriate strategies to control these parasites.
\end{abstract}

Methods: We cloned and sequenced part of the mitochondrial cytochrome $\mathrm{c}$ oxidase subunit I (COI) gene from $60 \mathrm{H}$. bovis isolates and $52 \mathrm{H}$. sinense isolates from five locations in Qinghai Province, China, to identify polymorphisms, and infer their phylogenetic relationships, historical population expansions, and divergence time.

Results: We identified $17 \mathrm{COI}$ haplotypes from the $\mathrm{H}$. bovis samples, and $23 \mathrm{COI}$ haplotypes from the $\mathrm{H}$. sinense samples. The haplotype and nucleotide diversities were 0.738 and 0.00202 for H. bovis, and 0.867 and 0.00300 for $\mathrm{H}$. sinense, respectively, which indicates rich genetic diversity in $\mathrm{H}$. bovis and $\mathrm{H}$. sinense populations. Bayesian phylogenetic analysis revealed that the two species are monophyletic, and geographical structuring of haplotypes was significantly different in $H$. sinense $(P<0.05)$, but not $H$. bovis. Neutrality tests and mismatch distribution statistical analysis revealed that populations of the two species have undergone demographic expansions. The divergence three Hypoderma spp. (H. bovis, H. lineatum, and H. sinense) was estimated to have occurred approximately 4.5 million years ago (Mya), which indicates that the rapid uplift of the Qinghai-Tibetan Plateau during the late Miocene-Pliocene was associated with divergence of Hypoderma species.

Conclusions: Results of the present study revealed that both $H$. bovis and $H$. sinense displayed high genetic diversity and widespread population genetic differentiation within and among populations; these data, along with the molecular phylogeny, demographic history, and divergence time estimation, provide new insight into evolutionary history of these species. These findings will help elucidate speciation in Hypoderma and provide theoretical basis for epidemiological surveillance and control of these species on the Qinghai-Tibetan Plateau.

Keywords: Hypoderma bovis, Hypoderma sinense, Hypodermosis, Cytochrome c oxidase I, Population genetics

\section{Background}

Hypoderma bovis and H. sinense (Diptera: Oestridae) are two species of flies in Oestridae and mainly parasitize cattle and yaks. The parasitizing flies are widely distributed in north and southwestern China [1,2]. The prevalence of Hypoderma spp. larval infection in yaks can reach

\footnotetext{
*Correspondence: 846751982@qq.com; Zhangym@nwsuaf.edu.cn

${ }^{2}$ Academy of Animal and Veterinary Medicine, Qinghai University, Xining, Qinghai 810016, China

'College of Veterinary Medicine, Northwest A \& F University, Yangling,

Shaanxi 712100, China

Full list of author information is available at the end of the article
}

up to $100 \%$ in some areas of Qinghai Province [3]. Hypodermosis of cattle and yaks, caused by the larvae of Hypoderma spp. , is responsible for substantial economic losses in the livestock industry because it results in spontaneous abortion, reduced milk production, loss of weight, reduced fertility, and poor hide quality $[4,5]$. Therefore, there is a need to develop effective strategies to control this disease.

The mitochondrial cytochrome $c$ oxidase subunit I (COI) gene is a molecular marker [6,7] used for taxonomic differentiation $[8,9]$, molecular identification $[10,11]$, and evolutionary studies $[12,13]$. Understanding the genetic 
diversity and population structure of pests are crucial for developing effective management strategies [14].

Therefore, in the present study, we analysed the genetic diversity of $H$. bovis and $H$. sinense based on mitochondrial COI sequences in samples collected from Qinghai Province, China. In addition, we investigated possible historical population expansions and divergence time of $H$. bovis and $H$. sinense. These findings are essential for understanding speciation of Hypoderma spp. and for epidemiological surveillance and control of these species on the Qinghai-Tibetan Plateau (QTP).

\section{Methods}

\section{Locations}

Hypoderma bovis and $H$. sinense were sampled from five localities in Qinghai Province, located in the northeastern part of the QTP in western China. The province covers a total area of over $721,000 \mathrm{~km}^{2}$, spanning approximately $1200 \mathrm{~km}$ east-west and $800 \mathrm{~km}$ northsouth, with an average elevation higher than $3000 \mathrm{~m}$ above sea level $[15,16]$. For $H$. bovis, sampling localities were in Maqin county (MQ), Haiyan county (HY), Huzhu county (HZ), Minhe county (MH), and Chengduo county (CD). For $H$. sinense, sampling localities were in Maqin county (MQ), Guinan county (GN), Haiyan county (HY), Tanggula town (TGL), and Chengduo county (CD) (Fig. 1).

\section{Sampling strategy}

We collected 60 third-stage $H$. bovis larvae and 52 thirdstage $H$. sinense larvae from five localities in Qinghai Province from 2013 to 2014 (Fig. 1). The initial identification of $H$. bovis and $H$. sinense was mainly based on morphological characteristics [17], and confirmed by molecular methods using the mitochondrial COI gene [8]. All specimens were fixed by immersion in $70 \%$ ethanol. The locations and sample numbers of $H$. bovis and $H$. sinense populations are shown in Table 1.

\section{DNA extraction, amplification, cloning, and sequencing}

The third-stage fly larvae were longitudinally cut to retrieve the internal organs. The genomic DNA was extracted from $10 \mathrm{mg}$ of each internal organ using a commercial kit (TIANamp Genomic DNA Kit, TIANGEN Biotechnology, Beijing, China) in accordance with the manufacturer's recommendations.

We used the primers UEA7 (5'-TACAGTTGGAATAGACGTTGATAC-3') and UEA10 (5'-TCCAATGCACTAATCTGCCATATTA-3') to amplify a partial DNA fragment of the COI gene [10]. Each PCR $(25 \mu \mathrm{L})$ was performed in a PCR tube that contained $1.0 \mu \mathrm{L}$ of each primer $(0.4 \mu \mathrm{M}), 8.5 \mu \mathrm{L}$ of $\mathrm{ddH}_{2} \mathrm{O}, 12.5 \mu \mathrm{L}$ of Taq PCR Master Mix (Sangon Biotechnology, Shanghai, China), and $2 \mu \mathrm{L}$ of DNA sample in a thermocycler (BIO-RAD, Hercules, USA). The cycling conditions used for PCR were $94{ }^{\circ} \mathrm{C}$ for $4 \mathrm{~min}$ (initial denaturation), $94{ }^{\circ} \mathrm{C}$ for $30 \mathrm{~s}$
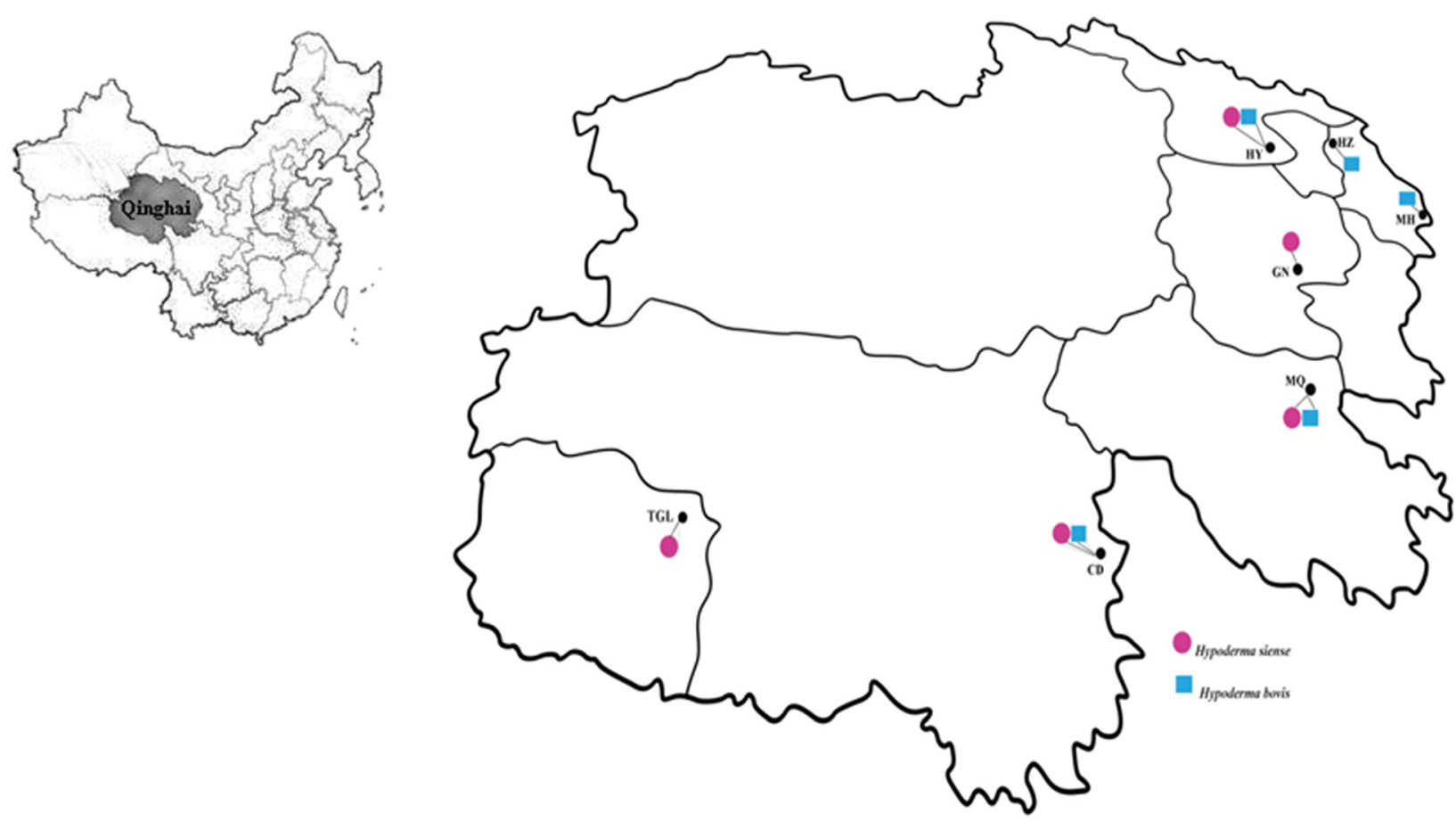

Fig. 1 Collection sites of $H$. bovis and $H$. sinense from Qinghai province of China. Population codes correspond to those in Table 1 
Table 1 Summary statistics observed in $H$. bovis and $H$. sinense populations in this study

\begin{tabular}{|c|c|c|c|c|c|c|c|c|}
\hline Species & Collection site & Population code & $\mathrm{n}$ & $\mathrm{NH}$ & $h$ & $\pi$ & Haplotype frequency & $\begin{array}{l}\text { GenBank accession } \\
\text { number }\end{array}$ \\
\hline \multirow[t]{6}{*}{ H. bovis } & & & 60 & 17 & 0.738 & 0.00202 & & \\
\hline & Maqin county & MQ & 13 & 8 & 0.923 & 0.00350 & $\begin{array}{l}\operatorname{HB} 1(3), \operatorname{HB} 2(1), \operatorname{HB} 3(2), \operatorname{HB} 4(2), \\
\operatorname{HB} 5(2), \operatorname{HB} 6(1), \operatorname{HB} 7(1), \operatorname{HB} 8(1)\end{array}$ & KT600277-КT600284 \\
\hline & Haiyan county & $\mathrm{HY}$ & 9 & 3 & 0.639 & 0.00105 & $\mathrm{HB} 3(5), \mathrm{HB} 7(3), \mathrm{HB} 9(1)$ & KT600279, KT600283, KT600285 \\
\hline & Huzhu county & $\mathrm{HZ}$ & 15 & 3 & 0.257 & 0.00077 & HB3(13), HB10(1), HB11(1) & KT600279, KT600286, KT600287 \\
\hline & Minhe county & $\mathrm{MH}$ & 15 & 5 & 0.676 & 0.00127 & $\begin{array}{l}\operatorname{HB} 3(8), \operatorname{HB} 12(1), \operatorname{HB} 13(4), \\
\operatorname{HB14}(1), \operatorname{HB} 15(1)\end{array}$ & KT600279, KT600288-KT600291 \\
\hline & Chengduo county & $C D$ & 8 & 6 & 0.929 & 0.00301 & $\begin{array}{l}\operatorname{HB} 3(2), \operatorname{HB} 7(1), \operatorname{HB} 8(2), \operatorname{HB} 13(1), \\
\operatorname{HB16}(1), \operatorname{HB17}(1)\end{array}$ & $\begin{array}{l}\text { KT600279, KT600283, KT600284, } \\
\text { KT600289, KT600292, KT600293 }\end{array}$ \\
\hline \multirow[t]{6}{*}{ H. sinense } & & & 52 & 23 & 0.867 & 0.00300 & & \\
\hline & Maqin county & MQ & 8 & 2 & 0.571 & 0.00083 & HS1(4), HS6(4) & KT600294, KT600299 \\
\hline & Guinan county & GN & 10 & 6 & 0.844 & 0.00297 & $\begin{array}{l}\operatorname{HS} 2(1), \operatorname{HS} 3(2), \operatorname{HS} 4(1), \operatorname{HS} 5(1) \\
\operatorname{HS} 6(4), \operatorname{HS} 7(1)\end{array}$ & KT600295-KT600300 \\
\hline & Haiyan county & $\mathrm{HY}$ & 11 & 10 & 0.982 & 0.00438 & $\begin{array}{l}\operatorname{HS} 1(2), \operatorname{HS} 3(1), \operatorname{HS} 6(1), \operatorname{HS} 8(1) \\
\operatorname{HSS} 9(1), \operatorname{HS} 10(1), \operatorname{HS} 11(1), \operatorname{HS} 12(1) \\
\operatorname{HS} 13(1), \operatorname{HS} 14(1)\end{array}$ & $\begin{array}{l}\text { KT600294, KT600296, KT600299, } \\
\text { KT600301-KT600307 }\end{array}$ \\
\hline & Tanggula town & TGL & 12 & 9 & 0.939 & 0.00345 & $\begin{array}{l}\operatorname{HS} 3(2), \operatorname{HS} 6(3), \operatorname{HS} 15(1), \operatorname{HS} 16(1) \\
\operatorname{HS} 17(1), \operatorname{HS} 18(1), \operatorname{HS} 19(1), \operatorname{HS} 20(1), \\
\operatorname{HS} 21(1)\end{array}$ & $\begin{array}{l}\text { KT600296, KT600299, } \\
\text { KT600308-KT600314 }\end{array}$ \\
\hline & Chengduo county & $C D$ & 11 & 4 & 0.764 & 0.00174 & HS1(4), HS6(4), HS22(1), HS23(2) & $\begin{array}{l}\text { KT600294, KT600299, KT600315, } \\
\text { KT600316 }\end{array}$ \\
\hline
\end{tabular}

$N$ number of individuals sequenced, $N H$ number of different haplotype, $h$ haplotype diversity, $\pi$ nucleotide diversity; The number of individuals observed for each haplotype is given in parentheses

(denaturation), $55{ }^{\circ} \mathrm{C}$ for $1 \mathrm{~min}$ (annealing), $72{ }^{\circ} \mathrm{C}$ for 1 min (extension) for 35 cycles, and a final extension at $72{ }^{\circ} \mathrm{C}$ for $10 \mathrm{~min}$. A negative control (without DNA template) was included in each amplification run. Each amplicon $(5 \mu \mathrm{L})$ was examined by $1.0 \%(\mathrm{w} / \mathrm{v})$ agarose gel electrophoresis to demonstrate amplification efficiency. The PCR products were purified using a DNA Agarose Gel Extraction Kit (Omega, Brattleboro, USA). The purified fragments were cloned into $\mathrm{pMD}^{\mathrm{rm}} 19-\mathrm{T}$ vector and subsequently transformed into Escherichia coli DH5 $\alpha$ (TaKaRa, Dalian, China). The recombinant plasmid DNA was obtained and then sequenced using an ABI 3730 DNA sequencer at Sangon Company (Shanghai, China).

\section{Population haplotype diversity analysis}

COI sequences were aligned using MEGA 5.2 [18]. Identical haplotypes were collapsed using DNASP 5.10 [19]. The number of haplotypes and standard diversity indices [haplotype and nucleotide diversities ( $h$ and $\pi$, respectively)] were calculated using DNASP 5.10 [19] for each population.

\section{Phylogenetic analysis and haplotype network construction}

Phylogenetic relationships of $H$. bovis and $H$. sinense COI haplotypes were inferred using Bayesian inference (BI). We selected the best-fit model $(G T R+I+G)$ for BI analyses for each data partition using Modeltest 3.7 [20] in conjunction with PAUP 4.0b10 [21]. A Bayesian tree was constructed using MrBayes 3.1.2 [22], and Markov chain Monte Carlo was run for 10 million generations with sampling every 1000 generations. The first $25 \%$ of generations were discarded as burn-in, and the remaining trees were used to estimate Bayesian posterior probabilities (PP).

COI sequences of $H$. bovis (AF497761) and $H$. sinense (AY350769) obtained from the GenBank database were used for phylogenetic analysis of the species in this study, and COI sequences from three other species of Hypoderma, H. lineatum (AF497762), H. tarandi (AF497764) and H. actaeon (AF497765), were used as in-group taxa for the phylogenetic analysis. Gasterophilus pecorum (AF497776) was selected as the out-group taxon to root the phylogenetic trees. Median-joining networks of all $H$. bovis and $H$. sinense haplotypes in this study were constructed using Network 4.6 [23] to visualize relationships among unique haplotypes.

\section{Population genetic and demographic history analyses}

Analysis of molecular variance (AMOVA) was used to evaluate $H$. bovis and $H$. sinense population genetic structure in Arlequin 3.11 with 1000 permutations [24]. This study implemented two levels of AMOVA for intraand inter-population analyses $\left(\Phi_{\mathrm{ST}}\right)$. Phylogeographic structure of $H$. bovis and $H$. sinense populations was 
estimated using PERMUT (http://www.pierroton.inra.fr/ genetics/labo/Software/Permut) with 1000 permutations. PERMUT tested phylogenetic structure by calculating $G_{S T}$ (only haplotype frequencies) and $\mathrm{N}_{\mathrm{ST}}$ (differences among haplotypes); phylogenetic structure is usually considered present when $\mathrm{N}_{\mathrm{ST}}$ is higher than $\mathrm{G}_{\mathrm{ST}}$ [25]. Fu's $F$ s and Tajima's $D$ neutrality tests, and sum of squared deviation (SSD) and Harpending's raggedness $(r g)$ test statistics of mismatch distributions were calculated to detect evidence of past population expansions in Arlequin 3.11 [26-28]. In addition, mismatch distributions of $H$. bovis and $H$. sinense populations were performed using DNASP 5.10 [19] to test whether demographic processes were consistent with the mismatch distribution test statistics. A population usually exhibits a uni-modal mismatch distribution when it has passed through a recent demographic expansion [29], whereas a multimodal mismatch distribution indicates that a population is comparatively stable [30].

Expansion time was estimated using the expectation $\tau=2$ ut [31], where $\tau$ represents the mode of the mismatch distribution, $t$ represents time in generations since expansion, and $u=2 \mu k$, where $\mu$ is the mutation rate (COI was estimated to be approximately $2 \%$ per million years for Hypoderma spp. ) [7] and $k$ is the length of the sequence [32]. The $H$. bovis and $H$. sinense generation time was estimated to be $1 \mathrm{y}$ based on their life-cycle [33].

\section{Divergence time estimates}

Divergence times were estimated using the Bayesian phylogenetic method implemented in BEAST 1.8.0 [34]. The clock model was set to relaxed, uncorrelated lognormal [35], with a Yule speciation tree model. Because there is a lack of Hypoderma fossils, a secondary calibration approach was used. Based on previous research on divergence time in Hypoderma spp. [10], a mean of normal distribution with standard deviation were set as 8.2 million years ago (Mya) with 0.5 Mya for $H$. tarandi and $H$. actaeon, and 4.2 Mya with 0.5 Mya for $H$. bovis and $H$. lineatum, respectively. The Markov chain Monte Carlo chain length was set to 10 million generations and sampled every 1000 generations. Chain convergence was assessed to determine effective sample sizes greater than 200 for all parameters using Tracer 1.5 [36], and trees were summarized using TreeAnnotator 1.8.1 [34].

\section{Results}

\section{Sequence variation and haplotype diversity}

There were no insertions or deletions of nucleotides in the 689-bp COI sequences amplified from any $H$. bovis and $H$. sinense. A total of 19 nucleotide polymorphisms (12 singleton variable sites and seven parsimony-informative sites) for $H$. bovis and 31 nucleotide polymorphisms (24 singleton variable sites and seven parsimony-informative sites) for $H$. sinense were detected. In total, 17 haplotypes were detected in $H$. bovis populations and 23 haplotypes were detected in $H$. sinense populations (Table 1$)$. Sequences of all haplotypes have been deposited in the GenBank under accession numbers KT600277-KT600316. The ratio of haplotypes relative to the total number of individuals sampled for each species was 0.28 for $H$. bovis and 0.44 for $H$. sinense. There was no significant difference in the number of haplotypes found in each sampling location between the two species $\left(F_{1,8}=0.459, P=0.517\right.$; Table 1). Values of $h$ and $\pi$ were 0.738 and 0.00202 for $H$. bovis, and 0.867 and 0.00300 for $H$. sinense, respectively, which indicates rich genetic diversity in $H$. bovis and $H$. sinense populations; however, there were no significant differences between the two species $\left(F_{1,8}=0.897, P=\right.$ $0.371 ; F_{1,8}=0.809, P=0.395$; Table 1 ).

\section{Phylogenetic analyses}

Bayesian analyses showed that all $H$. bovis haplotypes formed a single well-supported clade designated as clade $\mathrm{HB}(\mathrm{PP}=0.99$; Fig. 2), whereas all $H$. sinense haplotypes formed another well-supported clade designated as clade HS (PP = 0.99; Fig. 2).

The network for clade $\mathrm{HB}$ showed that Haplotype HB3 was considered the central haplotype, to which a large number of private haplotypes $(76.5 \%$ of the total haplotypes of clade $\mathrm{HB}$ ) were connected in a star-like manner (Fig. 2). The highest-frequency haplotype was HB3, followed by HB7, HB13, and HB8, which included $30,5,5$, and 3 individuals, respectively. For clade HS, Haplotype HS6 was considered the central haplotype. The private haplotypes represented $87.0 \%$ of all clade HS haplotypes. The highest-frequency haplotype was HS6, followed by HS1 and HS3, which included 16, 10, and 5 individuals, respectively, and they occupied a central position in the network (Fig. 2).

\section{Genetic differentiation and population structure}

AMOVA results showed that there was significant genetic differentiation in $H$. bovis and $H$. sinense populations (Table 2). For H. bovis, AMOVA showed that $11.88 \%$ of the variation was among populations and $88.12 \%$ was within populations. High genetic structure was found $\left(\Phi_{\mathrm{ST}}=0.119, P<0.001\right)$, which indicates remarkable genetic differentiation in $H$. bovis. For $H$. sinense, AMOVA showed that $7.83 \%$ of the variation was among populations and $92.17 \%$ was within populations. We also detected high genetic structure $\left(\Phi_{\mathrm{ST}}=0.078, P<0.001\right)$, which likewise indicates significant genetic differentiation, in the $H$. sinense isolates. Large pairwise $F_{\mathrm{ST}}$ values were found between $H$. bovis and $H$. sinense populations. For $H$. bovis, pairwise $F_{\mathrm{ST}}$ ranged from 0.009 to 0.190 , and most pairwise values were statistically significant (Table 3 ). For $H$. sinense, pairwise $F_{\mathrm{ST}}$ ranged from -0.037 to 0.210 , 


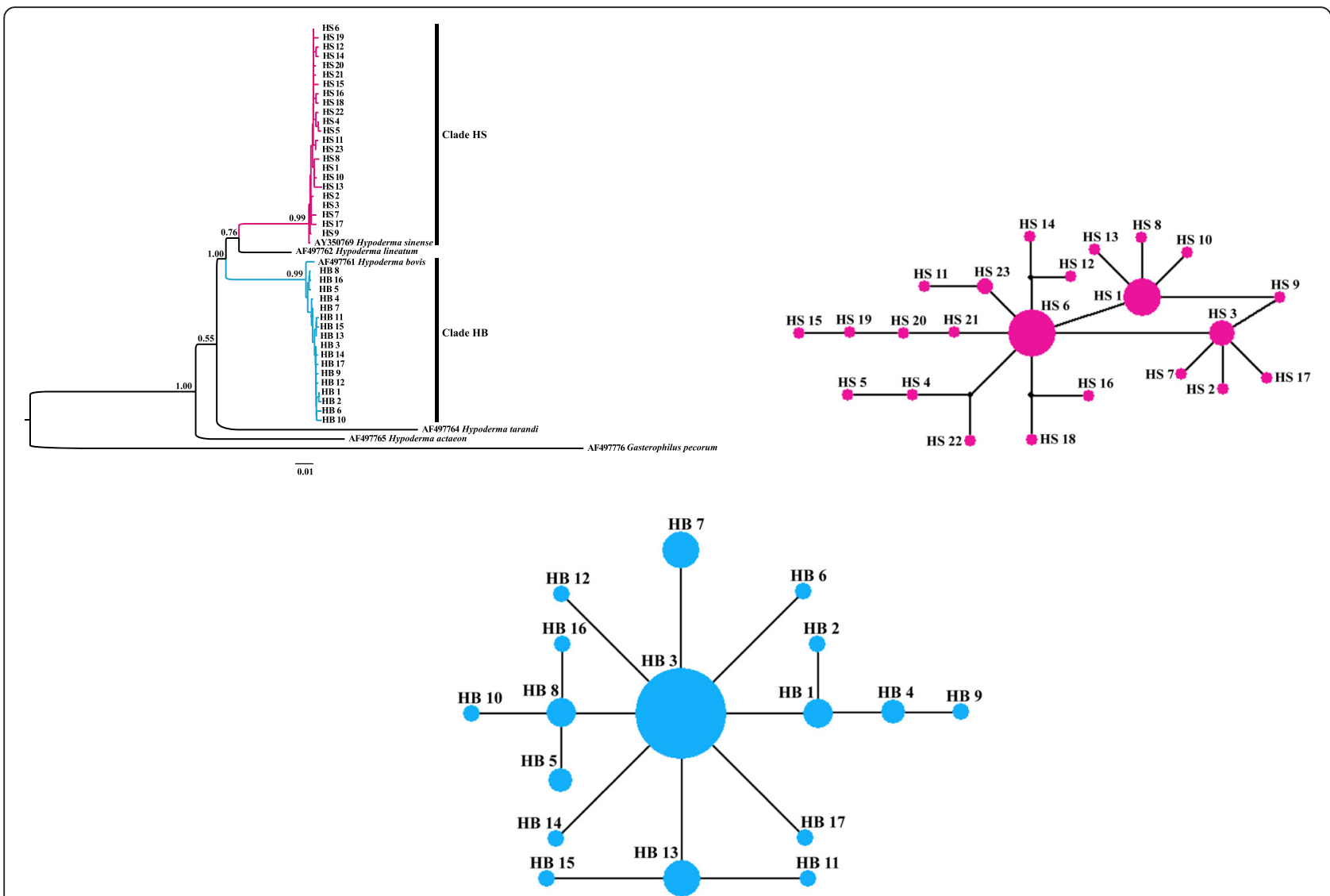

Fig. 2 The partitioned Bayesian phylogenetic tree and network of haplotypes for H. bovis and H. sinense based on COI haplotypes. (Left) Bayesian haplotypes phylogenetic tree of $\mathrm{H}$. sinense and $\mathrm{H}$. bovis based on $\mathrm{COI}$ gene sequences. Numbers on branches are Bayesian posterior probabilities. The black bars on the right indicate the corresponding clade HS and clade HB, and each clade (clade HS and clade HB) was presented with different colors. (Right) Median-joining network of haplotypes for $\mathrm{H}$. sinense and $\mathrm{H}$. bovis. The relative size of circles in the network is proportional to haplotype observed frequencies. The small black dots indicate hypothetical missing haplotypes. The haplotype colors correspond to $\mathrm{H}$. sinense and $H$. bovis in phylogenetic tree on the left. All haplotypes designations are listed in Table 1

and most pairwise values were also statistically significant (Table 3).

Demographic expansions were analysed for $H$. bovis and $H$. sinense populations using two neutrality tests and mismatch distributions. For H. bovis and H. sinense, Fu's $F s$ and Tajima's $D$ values were significantly negative (Table 4), and mismatch distributions of both species each showed a unimodal curve (Fig. 3). From the $\tau$ value (2.652) calculated by Arlequin, expansion of $H$. bovis populations was estimated to have occurred about 0.049 Mya; expansion of $H$. sinense populations $(\tau=3.098)$ occurred about 0.056 Mya. A permutation test showed that
$\mathrm{N}_{\mathrm{ST}}(0.141)$ was significantly higher than $\mathrm{G}_{\mathrm{ST}}(0.048)$ for $H$. sinense $(P<0.05)$, whereas $\mathrm{N}_{\mathrm{ST}}(0.116)$ was less than $\mathrm{G}_{\mathrm{ST}}(0.122)$ for $H$. bovis, which indicates that significant phylogeographic structure is apparent in $H$. sinense, but not H. bovis.

\section{Divergence times}

The estimated evolutionary timescale of five Hypoderma species with the $95 \%$ highest posterior densities (95\% HPD) intervals are presented in Fig. 4. Our analysis estimated that the most recent common ancestor of the five Hypoderma species existed approximately 8.1 Mya (95\%

Table 2 Analysis of molecular variance (AMOVA) of COI data from the populations of the two Hypoderma species

\begin{tabular}{|c|c|c|c|c|c|c|c|c|}
\hline \multirow[t]{2}{*}{ Source of variation } & \multicolumn{4}{|c|}{ H. bovis } & \multicolumn{4}{|c|}{$H$. sinense } \\
\hline & $\overline{d f}$ & SS & $\%$ & $\overline{\text { Fixation index }}$ & $\overline{d f}$ & SS & $\%$ & $\overline{\text { Fixation index }}$ \\
\hline Among populations & 4 & 6.500 & 11.88 & & 4 & 7.260 & 7.83 & \\
\hline Within populations & 55 & 34.467 & 88.12 & $\Phi_{\mathrm{ST}}=0.119^{* * *}$ & 47 & 45.374 & 92.17 & $\Phi_{\mathrm{ST}}=0.078^{* * *}$ \\
\hline
\end{tabular}

$d f$ degree of freedom, SS sum of squares, \% percentage of variation, $\Phi_{S T}$ fixation index; ${ }^{* * *} P<0.001$ 
Table 3 Pairwise $F_{\text {ST }}$ values among populations for $H$. bovis and $H$. sinense using $C O I$ sequences

\begin{tabular}{|c|c|c|c|c|c|c|c|c|c|c|c|}
\hline \multicolumn{6}{|c|}{ H. bovis } & \multicolumn{6}{|c|}{$H$. sinense } \\
\hline PA & $\mathrm{MQ}$ & $\mathrm{HY}$ & $\mathrm{HZ}$ & $\mathrm{MH}$ & $C D$ & PA & $\mathrm{MQ}$ & GN & $\mathrm{HY}$ & $\mathrm{TGL}$ & $C D$ \\
\hline MQ & 0.000 & & & & & MQ & 0.000 & & & & \\
\hline $\mathrm{HY}$ & $0.095^{*}$ & 0.000 & & & & GN & $0.210^{*}$ & 0.000 & & & \\
\hline $\mathrm{HZ}$ & $0.119^{*}$ & $0.127^{*}$ & 0.000 & & & $\mathrm{HY}$ & -0.034 & $0.116^{*}$ & 0.000 & & \\
\hline $\mathrm{MH}$ & $0.152^{*}$ & $0.176^{*}$ & 0.067 & 0.000 & & TGL & $0.123^{*}$ & 0.016 & $0.095^{*}$ & 0.000 & \\
\hline$C D$ & 0.009 & $0.142^{*}$ & $0.190^{*}$ & $0.171^{*}$ & 0.000 & $C D$ & -0.037 & $0.146^{*}$ & 0.003 & $0.092^{*}$ & 0.000 \\
\hline
\end{tabular}

$P A$ population abbreviation; ${ }^{*} P<0.05$

HPD: 6.8-8.8 Mya). The split between two main clades of the three Hypoderma species (H. bovis, $H$. lineatum, and $H$. sinense) occurred about 4.5 Mya (95 \% HPD: 3.1-5.3 Mya), and the divergence time between $H$. sinense and $H$. lineatum was approximately 3.7 Mya (95 \% HPD: 2.2-4.9 Mya). Intraspecific divergence times all occurred within 3.1 Mya for $H$. bovis and $H$. sinense.

\section{Discussion}

The haplotype $(h)$ and nucleotide $(\pi)$ diversity are important indicators of genetic diversity in a population [19]. The results showed high $h$ and $\pi$ in $H$. bovis and $H$. sinense populations, which indicates rich genetic diversity of populations of the two species and might explain why the two species have a broad tolerance to environmental and habitat stresses; fast mutational processes inherent in individuals and populations may enable these two Hypoderma spp. to successfully adapt to complex environments.

The Bayesian phylogenetic analysis strongly supported the coalescence of COI haplotypes within $H$. bovis and $H$. sinense $(P P=0.99$; Fig. 2$)$, which supports the notion that these are different species and is consistent with of the findings of a previous molecular study [8]. In this tree, $H$. sinense and $H$. lineatum $(P P=0.76$; Fig. 2$)$ were more closely related to each other than to $H$. bovis. This result was not consistent with that of a previous molecular study [37]. This is probably due to the use of different molecular markers and phylogenetic analysis methods. Therefore, more molecular markers and phylogenetic analysis methods should be applied in future studies to resolve this inconsistency. The medianjoining networks showed that private haplotypes of $H$.

Table 4 Results of the neutrality tests calculated and values of the mismatch distribution test statistics for $\mathrm{H}$. bovis and $\mathrm{H}$. sinense based on $\mathrm{COI}$ sequences

\begin{tabular}{lllll}
\hline Species & Fu's FS & Tajima's D & SSD & rg \\
\hline H. bovis & $-12.795^{* * *}$ & $-2.031^{* *}$ & 0.001 & 0.035 \\
H. sinense & $-19.809^{* * *}$ & $-2.320^{* *}$ & 0.001 & 0.033 \\
\hline
\end{tabular}

Fu's FS Fu's Fs test statistic, Tajima's D Tajima's D Test statistic, SSD sum of squared deviation, rg Harpending's raggedness statistic; ${ }^{* *} P<0.01 ;{ }^{* * *} P<0.001$ bovis and $H$. sinense were derived from dominant haplotypes (Fig. 2), and the percentages of private haplotypes were high $(H$. bovis: $76.5 \%$ of total haplotypes; $H$. sinense: $87.0 \%$ of total haplotypes), which indicates that populations of the two Hypoderma species were closely related respectively, and speciation within Hypoderma might be relatively complex.

AMOVA indicated that genetic structure was substantially higher within than among populations (within populations: $88.12 \%$ for $H$. bovis and $92.17 \%$ for $H$. sinense; among populations: $11.88 \%$ for $H$. bovis and $7.83 \%$ for $H$. sinense). Therefore, the majority of $H$. bovis and $H$. sinense genetic differentiation was intra-population. This result may be caused by gene flow. QTP uplift, which resulted in topography changes [38], limited gene flow among the populations, and might have led to gene flow that primarily occurred within the populations; this was likely exacerbated because Hypoderma species cannot fly long distances, and adults live for a very short time (only 5-6 days) [39]. Genetic structure among populations was significant $(P<0.001)$ for $H$. bovis and $H$. sinense based on AMOVA (Table 2), which indicates that significant population differentiation occurred between populations of these two species. $F_{\mathrm{ST}}$ is used to assess genetic differentiation among closely related populations [40]. Our assessment of population genetic structure using the $F_{\mathrm{ST}}$ index revealed that the range of pairwise $F_{\mathrm{ST}}$ values is narrower in $H$. bovis (0.009 to 0.190) than in $H$. sinense ( -0.037 to 0.210$)$, indicating greater genetic differentiation among $H$. sinense than in $H$. bovis populations. In addition, permutation test showed that $H$. sinense had greater geographic structure of $h$ than $H$. bovis. Geographic structure of natural populations is determined by many factors, such as life history, population size, ecological traits, habitat, and historical events [41, 42]. Our results may be caused, in part, by inconsistent habitat in this study for $H$. bovis and $H$. sinense. However, geographic genetic structure was previously shown to negatively correlate with dispersal abilities [43]. In the present research, $H$. sinense exhibited greater geographic genetic structure than $H$. bovis, indicating that dispersal ability is higher in $H$. bovis than $H$. sinense. This finding is consistent with the life 

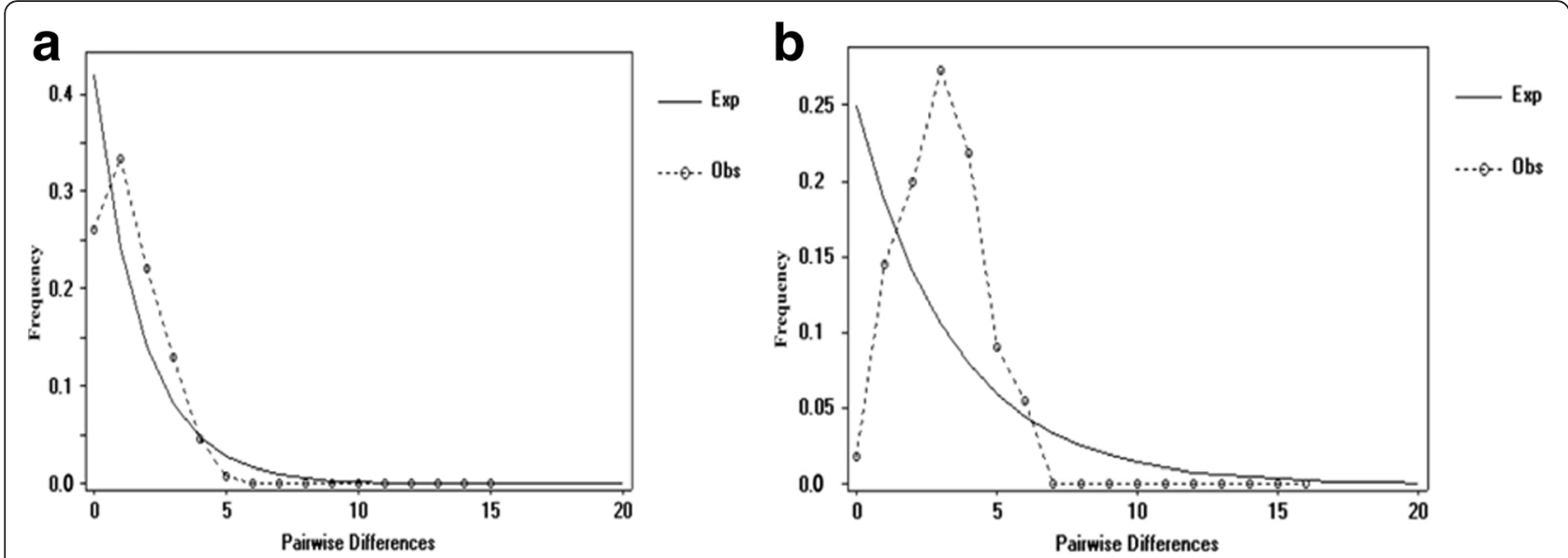

Fig. 3 Mismatch distribution analysis for total populations of H. bovis and H. sinense using DNASP 5.10. Graphs of the mismatch distributions of (a) H. bovis populations and (b) H. sinense populations. The $\mathrm{X}$ axis shows the observed distribution of pairwise nucleotide differences, and the $Y$ axis shows the frequencies. The dotted lines with circles represent the observed frequency of pairwise differences, and the solid lines show the expected values under the sudden population expansion model

history of these species; $H$. bovis mainly parasitize cattle and yaks in plains, hills, and plateaus, whereas $H$. sinense mainly attack bovines in plateau settings [1]. Overall, these results indicate that genetic structure may differ between Hypoderma species with differences in habitat preference and dispersal ability.

In this study, the neutrality tests were significantly negative for $H$. bovis and $H$. sinense populations, which indicates that population expansion events may have occurred in the demographic history of $H$. bovis and $H$. sinense. Additionally, the mismatch population test statistics $r g$ and SSD for both $H$. bovis and $H$. sinense populations were small and not statistically significant; this indicates that the sudden expansion model, which corresponded with a unimodal curve of the mismatch distribution analysis, could not be rejected (Fig. 3).

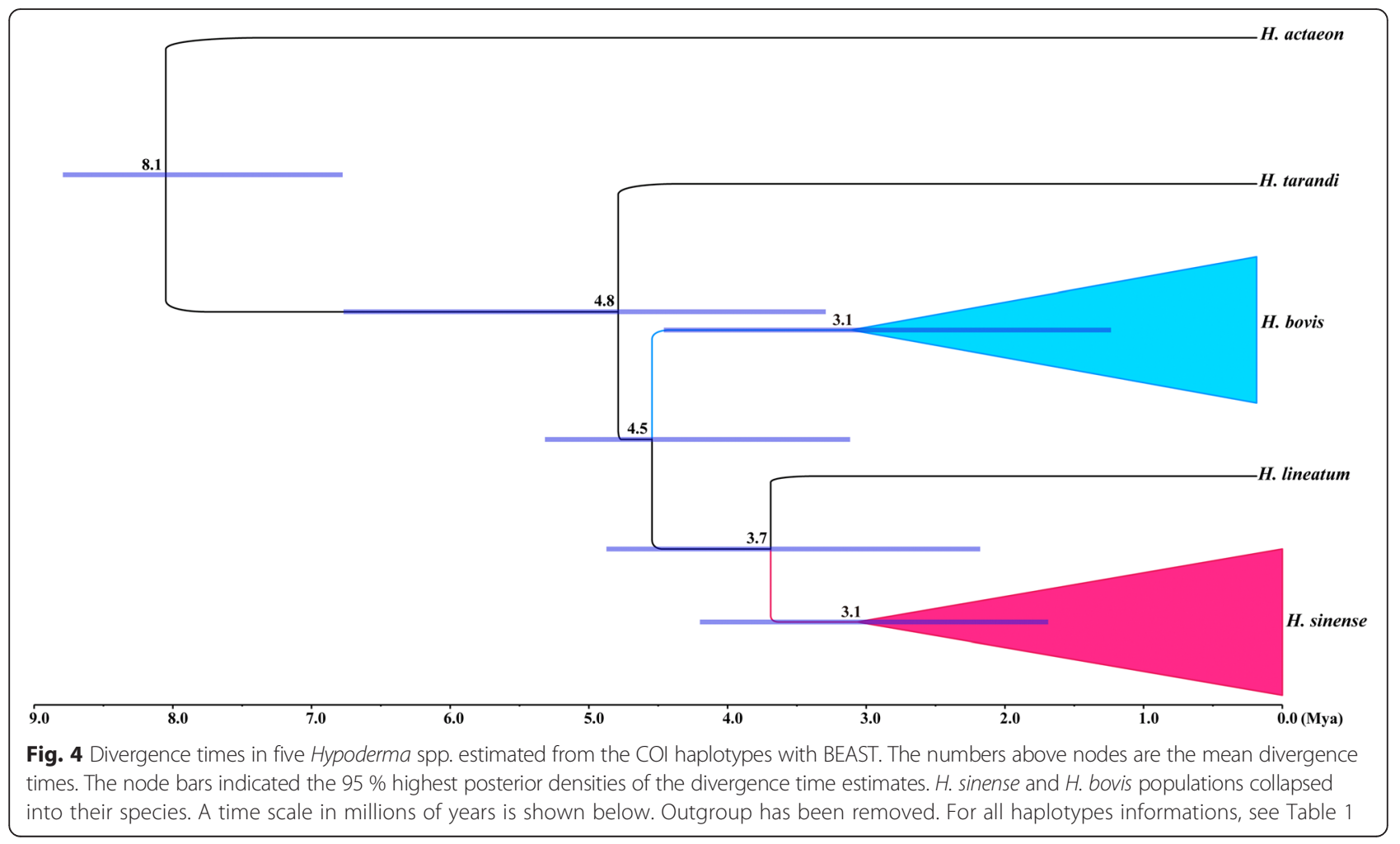


Overall, these analyses indicated that a demographic expansion had occurred in the $H$. bovis and $H$. sinense populations. $\tau$ values reflected estimated expansion times of 0.049 Mya for $H$. bovis and 0.056 Mya for $H$. sinense, which correspond to the late Pleistocene [44, 45]. These expansions probably occurred because $H$. bovis and $H$. sinense populations on the Tibetan Plateau experienced geological changes and climatic oscillations during the QTP uplift and Quaternary glaciation, which may have also led to population differentiation of $H$. bovis and $H$. sinense. After QTP uplift and Quaternary glaciation, many private haplotypes may have been derived from the dominant $H$. bovis and $H$. sinense haplotypes during expansion phases, which resulted in the starlike haplotype networks (Fig. 2).

The COI gene is a global molecular clock gene [46]. In this study, BEAST analyses of COI results estimated that the three Hypoderma species (H. bovis, H. lineatum, and $H$. sinense) diverged approximately 4.5 Mya, which indicates a late Miocene-Pliocene split among $H$. bovis, $H$. lineatum and $H$. sinense [47, 48]. Climatic changes during the late Miocene-Pliocene might have played an important role in the divergence of Hypoderma spp. Furthermore, the divergence time between $H$. sinense and $H$. lineatum was estimated to be 3.7 Mya, which mainly corresponded to the rapid uplift of the QTP approximately 3.6 Mya [49] and therefore indicates that rapid uplift of the QTP could have greatly influenced the divergence of Hypoderma spp. More importantly, the rapid uplift of the QTP changed topography, strengthened the East Asia monsoon, and modified global climate [50-52], which may have led to the divergence and speciation of many organisms [5355]. Therefore, our results indicate that the rapid uplift of the QTP led to habitat isolation, mutation accumulation, and fragmentation in Hypoderma populations, and eventually caused speciation of $H$. bovis, $H$. lineatum and $H$. sinense.

Hypoderma spp. play a critical role in production losses and susceptibility of cattle and yaks to disease $[7,56,57]$. Our study may be a first step toward a better understanding of Hypoderma evolutionary history and speciation, and provides important information for the future study of epidemiological surveillance and hypodermosis control on the QTP.

\section{Conclusions}

This is the first characterization of the genetic diversity and population structure using mitochondrial COI sequences of $H$. bovis and $H$. sinense populations in Qinghai Province, China. The results support the distinction of the two species of Hypoderma based on genetic diversity and divergence. Most genetic differentiation of $H$. bovis and $H$. sinense was found within populations, which may have been caused by QTP uplift and life history of the species. Further research including more molecular markers, increased sampling, and different phylogenetic analysis methods are necessary to elucidate genetic differentiation of Hypoderma spp. in more detail. In addition, the current findings provide fundamental evolutionary information regarding $H$. bovis and $H$. sinense. These findings also provide a molecular baseline for the control and elimination of Hypoderma spp. on the QTP.

\section{Abbreviations}

BI: Bayesian inference; COI: Cytochrome c oxidase subunit l; $h$ : Haplotype diversity; MCMC: Markov chain Monte Carlo; Mya: Million years ago:

PP: Posterior probabilities; QTP: Qinghai-Tibetan plateau; $\pi$ : Nucleotide diversity.

\section{Competing interests}

The authors declare that they have no competing interests.

\section{Authors' contributions}

YMZ and WL conceived and designed the study, and critically revised the manuscript. YF performed the experiments, analysed the data and drafted the manuscript. HD, ZHG and YL helped the collection of samples. All authors read and approved the final manuscript.

\section{Acknowledgments}

This work was supported by the National Natural Science Foundation of China (Grant No. 31360588), the International Scientific and Technological Cooperation project of Qinghai Province (Grant No. 2013-H-804), the agricultural science and technology achievements transformation and extension of Qinghai province (No. 2014-NS-505), and the International Scientific and Technological Cooperation project of National Science and Technology Ministry (Grant No. 2015DFG31870).

\section{Author details}

${ }^{1}$ College of Veterinary Medicine, Northwest A \& F University, Yangling, Shaanxi 712100, China. ${ }^{2}$ Academy of Animal and Veterinary Medicine, Qinghai University, Xining, Qinghai 810016, China. ${ }^{3}$ College of Agriculture and Animal Husbandry, Qinghai University, Xining, Qinghai 810016, China.

Received: 5 November 2015 Accepted: 1 March 2016

Published online: 12 March 2016

\section{References}

1. Yin H, Ma M, Yuan G, Huang S, Liu Z, Luo J, Guan G. Hypodermosis in China. J Anim Vet Adv. 2003;2:179-83

2. Otranto D, Colwell DD, Pape T. Hypoderma sinense : solving a century-old enigma. Med Vet Entomol. 2005;19:315-21.

3. Li W, Nasu T, Ma YQ, Zhu XY, Rende S, Makimura S. Migration of warble fly larvae in the yak and optimum timing of ivermectin treatment. J Vet Med Sci. 2004:66:891-2.

4. Otranto D, Paradies P, Testini G, Lia RP, Giangaspero A, Traversa D, Colwell DD. First description of the endogenous life cycle of Hypoderma sinense affecting yaks and cattle in China. Med Vet Entomol. 2006:20:325-8.

5. Li W, Fu Y, Duo H, Guo ZH, Shen XY, Huang FQ, Feng K, Dang ZS, Peng M, Wang F, Nasu T, Nonaka N. An epidemiological study of hypoderma infection and control using ivermectin in yaks in Qinghai province. China J Vet Med Sci. 2014;76(2):183-8.

6. Simon C, Frati F, Beckenbach A, Crespi B, Liu H, Flook P. Evolution, weighting and phylogenetic utility of mitochondrial gene sequences and a compilation of conserved polymerase chain reaction primers. Ann Entomol Soc Am. 1994;87:651-701.

7. Otranto D, Traversa D, Guida B, Tarsitano E, Fiorente P, Stevens JR. Molecular characterization of the mitochondrial cytochrome oxidase I gene of oestridae larvae causing obligate myiasis. Med Vet Entomol. 2003;17:307-15.

8. Otranto D, Traversa D, Colwell DD, Guan G, Giangaspero A, Boulard C, Yin H. A third species of Hypoderma (Diptera: Oestridae) affecting cattle and yaks in China: molecular and morphological evidence. J Parasitol. 2004;90:958-65.

9. Sun Y, Li Q, Kong LF, Zhang XD. DNA barcoding of Caenogastropoda along coast of China based on the COI gene. Mol Ecol Resour. 2012;12(2):209-18. 
10. Otranto D, Colwell DD, Traversa D, Stevens JR. Species identification of Hypoderma affecting domestic and wild ruminants by morphological and molecular characterization. Med Vet Entomol. 2003;17:316-25.

11. Li W, Ano H, Jin JH, Nasu T, Ma YQ, Zhu XY, Makimura S. Cytochrome oxidase I gene sequence of Hypoderma sinense infecting yaks in the Qinghai-Tibet high plateau of China. Vet Parasitol. 2004;124:131-5.

12. Otranto D, Traversa D, Tarsitano E, Stevens J. Molecular differentiation of Hypoderma bovis and Hypoderma lineatum (Diptera, Oestridae) by polymerase chain reaction-restriction fragment length polymorphism (PCRRFLP). Vet Parasitol. 2003;112:197-201.

13. Monte TCC, Simões RO, Oliveira APM, Novaes CF, Thiengo SC, Silva AJ, Estrela PC, Júnior AM. Phylogenetic relationship of the Brazilian isolates of the rat lungworm Angiostrongylus cantonensis (Nematoda: Metastrongylidae) employing mitochondrial COI gene sequence data. Parasites \& Vectors. 2012;248(5):1-9.

14. Wei DD, Yuan ML, Wang BJ, Zhou AW, Dou W, Wang JJ. Population genetics of two asexually and sexually reproducing psocids species inferred by the analysis of mitochondrial and nuclear DNA sequences. PLoS One. 2012;7(3):e33883.

15. Zhang DD, Jim CY, Peart MR, Shi C. Rapid changes of precipitation pH in Qinghai Province, the northeastern Tibetan Plateau. Sci Total Environ. 2003; 305(1-3):241-8.

16. Fang XM, Zhang WL, Meng QQ, Gao JP, Wang XM, King J, Song CH, Dai S, Miao YF. High-resolution magnetostratigraphy of the Neogene Huaitoutala section in the eastern Qaidam Basin on the NE Tibetan Plateau, Qingha Province, China and its implication on tectonic uplift of the NE Tibetan Plateau. Earth Planet Sci Lett. 2007;258:293-306.

17. Li W, Nasu T, Ma YQ, Zhu XY, Makimura S. Scanning electron microscopic study of third-instar warbles in yak in China. Vet Parasitol. 2004;121:167-72.

18. Tamura K, Peterson D, Peterson N, Stecher G, Nei M, Kumar S. MEGA5: Molecular evolutionary genetics analysis using maximum likelihood, evolutionary distance, and maximum parsimony methods. Mol Biol Evol. 2011;28:2731-9.

19. Librado P, Rozas J. DnaSP v5: a software for comprehensive analysis of DNA polymorphism data. Bioinformatics. 2009;25:1451-2.

20. Posada D, Crandall KA. Modeltest: testing the model of DNA substitution. Bioinformatics. 1998;14:817-8.

21. Swofford DL. PAUP*: phylogenetic analysis using parsimony (* and othermethods) 4.0b10. Sunderland, Massachusetts. USA: Sinauer Associates; 2002.

22. Ronquist F, Huelsenbeck JP. MrBayes 3: Bayesian phylogenetic inference under mixed models. Bioinformatics. 2003;19:1572-4.

23. Bandelt HJ, Forster $P$, Röhl A. Median-joining networks for inferring intraspecific phylogenies. Mol Biol Evol. 1999;16:37-48.

24. Excoffier L, Laval G, Schneider S. Arlequin (version 3.0): an integrated software package for population genetics data analysis. Evol Bioinform. 2005;1:47-50.

25. Pons $\mathrm{O}$, Petit RJ. Measuring and testing genetic differentiation with ordered versus unordered alleles. Genetics. 1996;144:1237-45.

26. Dsouli-Aymes N, Michaux J, Stordeur ED, Couloux A, Veuille M, Duvallet G. Global population structure of the stable fly (Stomoxys calcitrans) inferred by mitochondrial and nuclear sequence data. Infect Genet Evol. 2011;11:334-42.

27. Tajima F. Statistical method for testing the neutral mutation hypothesis by DNA polymorphism. Genetics. 1989;123:585-95.

28. Fu YX. Statistical tests of neutrality of mutations against population growth, hitchhiking and background selection. Genetics. 1997;147:915-25.

29. Excoffier L. Patterns of DNA sequence diversity and genetic structure after a range expansion: lessons from the infinite-island model. Mol Ecol. 2004;13:853-64.

30. Slatkin M, Hudson RR. Pairwise comparisons of mitochondrial DNA sequences in stable and exponentially growing populations. Genetics. 1991;129:555-62.

31. Rogers AR. Genetic evidence for a Pleistocene population expansion. Evolution. 1995:49:608-15.

32. Rogers $A R$, Harpending $H$. Population growth makes waves in the distribution of pairwise genetic differences. Mol Biol Evol. 1992;9:552-69.

33. Xue WQ, Zhao JM. Flies of China. Shenyang: Liaoning Science and Technology Press; 1994. p. 2244-50.

34. Drummond AJ, Suchard MA, Xie D, Rambaut A. Bayesian phylogenetics with BEAUti and the BEAST 1.7. Mol Biol Evol. 2012;29:1969-73.

35. Drummond AJ, Ho SYW, Phillips MJ, Rambaut A. Relaxed phylogenetics and dating with confidence. PLoS Biol. 2006;4:e88.

36. Rambaut A, Drummond AJ. Tracer v.1.4. 2007; Available: http://tree.bio.ed.ac. uk/software/Tracer/.
37. Weigl S, Traversa D, Testini G, Dantas-Torres F, Parisi A, Colwell DD, Otranto $D$. Analysis of a mitochondrial noncoding region for the identification of the most diffused Hypoderma species (Diptera, Oestridae). Vet Parasitol. 2010;173:317-23.

38. Wang CS, Zhao XX, Liu ZF, Lippert PC, Graham SA, Coe RS, Yi HS, Zhu LD, Liu S, Li YL. Constraints on the early uplift history of the Tibetan Plateau. Proc Natl Acad Sci U S A. 2008;105:4987-92.

39. Zumpt F. Myiasis in man and animals in the old world. London: Butterworths: 1965, p. 217-29.

40. Weir BS, Cockerham CC. Estimating F-Statistics for the analysis of population structure. Evolution. 1984:38:1358-70.

41. Hewitt GM. Genetic consequences of climatic oscillations in the Quaternary. Phil Trans Roy Soc London (Ser B). 2004;359:183-95.

42. Chen ST, Xing YW, Su T, Zhou ZK, Dilcher ED L, Soltis DE. Phylogeographic analysis reveals significant spatial genetic structure of Incarvillea sinensis as a product of mountain building. BMC Plant Biol. 2012;12:1-12.

43. Bilton DT, Freeland JR, Okamura B. Dispersal in freshwater invertebrates. Mol Biol Evol. 2001;32:159-81.

44. Shi YF. Characteristics of late Quaternary monsoonal glaciation on the Tibetan plateau and in East Asia. Quatern Int. 2002;97-98:79-91.

45. Zhang DF, Fengquan L, Jianmin B. Eco-environmental effects of the Qinghai-Tibet plateau uplift during the Quaternary in China. Environ Geol. 2000;39:1352-8

46. Gaunt MW, Miles MA. An insect molecular clock dates the origin of the insects and accords with palaeontological and biogeographic landmarks. Mol Biol Evol. 2002;19:748-61.

47. Harrison TM, Copeland P, Kidd W, Yin A. Raising Tibet. Science. 1992;255: 1663-70.

48. An ZS, Kutzbach JE, Prell WL, Porter SC. Evolution of Asian monsoons and phased uplift of the Himalaya-Tibetan plateau since late Miocene times. Nature. 2001:411:62-6.

49. Li JJ, Fang XM. Research on the uplift of the Qinghai-Xizang Plateau and environmental changes. Chinese Sci Bull. 1998:43:1569-74.

50. Qiang XK, Li ZX, Powell CM, Zheng HB. Magnetostratigraphic record of the Late Miocene onset of the East Asian monsoon and Pliocene uplift of northern Tibet. Earth Planet Sc Lett. 2001;187:83-93.

51. Kutzbach JE, Guetter PJ, Ruddiman WF, Prell WL. The sensitivity of climate to late Cenozoic uplift in Southern Asia and the American west: Numerical experiments. J Geophys Res. 1989;94:18393-407.

52. Raymo ME, Ruddiman WF. Tectonic forcing of late Cenozoic climate change. Nature. 1992;359:117-22.

53. Young A, Boyle T, Brown A. The population genetic consequences of habitat fragmentation for plants. Trends Ecol Evol. 1996;11:413-8.

54. Fahrig L. Effects of habitat fragmentation on biodiversity. Annu Rev Eco Evol S. 2003;34:487-515.

55. Yang FS, Qin AL, Li YF, Wang XQ. Great genetic differentiation among populations of Meconopsis integrifolia and its implication for plant speciation in the Qinghai-Tibetan Plateau. PLoS One. 2012;7(5):e37196.

56. Colwell DD, López C, Diez-Baňos P, Morrondo P, Panadero R. Impact of previous infestation on dynamics of circulating hypodermin $C$ in cattle artificially infested with Hypoderma lineatum (Diptera: Oestridae). Vet Parasitol. 2008;154:114-21.

57. Boulard C. Durably controlling bovine hypodermosis. Vet Res. 2002;33:455-64.

\section{Submit your next manuscript to BioMed Central and we will help you at every step:}

- We accept pre-submission inquiries

- Our selector tool helps you to find the most relevant journal

- We provide round the clock customer support

- Convenient online submission

- Thorough peer review

- Inclusion in PubMed and all major indexing services

- Maximum visibility for your research

Submit your manuscript at www.biomedcentral.com/submit 